\title{
Expression of p53 Target Genes in the Early Phase of Long-Term Potentiation in the Rat Hippocampal CA1 Area
}

\author{
Vladimir O. Pustylnyak, ${ }^{1,2,3}$ Pavel D. Lisachev, ${ }^{2,4}$ and Mark B. Shtark ${ }^{2}$ \\ ${ }^{1}$ Novosibirsk State University, Pirogova Street 2, Novosibirsk 630090, Russia \\ ${ }^{2}$ Institute of Molecular Biology and Biophysics SB RAMS, Timakova Street 2, Novosibirsk 630117, Russia \\ ${ }^{3}$ International Tomography Center (ITC) SB RAS, Institutskaya Street 3-A, Novosibirsk 630090, Russia \\ ${ }^{4}$ Laboratory of Biomedical Informatics, Design Technological Institute of Digital Techniques SB RAS, \\ Akademika Rzhanova Street 6, Novosibirsk 630090, Russia
}

Correspondence should be addressed to Vladimir O. Pustylnyak; pustylnyak@ngs.ru

Received 17 October 2014; Accepted 27 January 2015

Academic Editor: Michel Baudry

Copyright (C) 2015 Vladimir O. Pustylnyak et al. This is an open access article distributed under the Creative Commons Attribution License, which permits unrestricted use, distribution, and reproduction in any medium, provided the original work is properly cited.

\begin{abstract}
Gene expression plays an important role in the mechanisms of long-term potentiation (LTP), which is a widely accepted experimental model of synaptic plasticity. We have studied the expression of at least 50 genes that are transcriptionally regulated by p53, as well as other genes that are related to p53-dependent processes, in the early phase of LTP. Within 30 min after Schaffer collaterals (SC) tetanization, increases in the mRNA and protein levels of Bax, which are upregulated by p53, and a decrease in the mRNA and protein levels of $\mathrm{Bcl} 2$, which are downregulated by $\mathrm{p} 53$, were observed. The inhibition of Mdm 2 by nutlin- 3 increased the basal 553 protein level and rescued its tetanization-induced depletion, which suggested the involvement of Mdm2 in the control over p53 during LTP. Furthermore, nutlin-3 caused an increase in the basal expression of Bax and a decrease in the basal expression of $\mathrm{Bcl} 2$, whereas tetanization-induced changes in their expression were occluded. These results support the hypothesis that p53 may be involved in transcriptional regulation during the early phase of LTP. We hope that the presented data may aid in the understanding of the contribution of p53 and related genes in the processes that are associated with synaptic plasticity.
\end{abstract}

\section{Introduction}

The storage of information in the brain relies on long-term synaptic plasticity, which depends on complex molecular interactions involving gene expression. One of the forms of synaptic plasticity is hippocampal long-term potentiation (LTP). The late phase of LTP is known to be dependent on mRNA and protein synthesis during a brief time after stimulus [1].

Several transcription factors are rapidly induced in association with LTP [2]. We demonstrated earlier that the tetanization of SC in rat hippocampal slices, which induces the long-term potentiation of CA3-CA1 synapses, is accompanied by a brief (less than $40 \mathrm{~min}$ ) increase in the binding of transcription factor p53 with the promoter of S100B and by an increase in the level of S100B mRNA [3]. Interestingly, the maximal increase in the DNA-binding activity of p53 coincided with the maximal rate of decrease in the p53 protein level, which suggested the activation of negative feedback to $\mathrm{p} 53$.

p53 is a key regulator of the cell cycle and "programmed cell death" (apoptosis). Biological functions of p53 are primarily mediated through the transcriptional regulation of target genes $[4,5]$. Under stress conditions, the increased activity of p53 can increase the susceptibility of cells to death signals by shifting the balance between proapoptotic (Bax, Noxa, and Puma) and antiapoptotic (Bcl2, Birc5) proteins of the Bcl2 family, which regulate the activity of proteolytic enzymes called caspases. In addition, p53 can induce the expression of "death receptors," which initiate apoptosis by the binding of their cognate ligands. Thus, upon activation, p53 can induce apoptosis by the activation of caspases through multiple mechanisms [6].

p53 is widely known primarily due to its ability to suppress tumors; however, the list of its functions is growing. Accumulating evidence suggests that p53 should be viewed 
as a crucial decision-maker molecule rather than as a tumor suppressor protein $[5,7]$. p53, caspases, and Bcl-2 family members can regulate the proliferation and differentiation of neural progenitor cells, as well as neurite outgrowth and regeneration [7, 8]. The activation of caspases, which is regulated by $\mathrm{Bcl} 2$ family proteins, seems to be necessary for synaptic modifications during long-term depression [9] and to contribute to LTP [10]. Another p53 transcriptional target, microRNA-34a, also regulates neurite outgrowth, spinal morphology, and function [11]. Finally, p53 regulates the transcription of genes that encode secreted proteins, such as interleukin 6, TNF- $\alpha$, and S100B, which can modulate synaptic plasticity $[12,13]$.

Thus, which functional consequences might the brief activation of $\mathrm{p} 53$ have? The control of the transcriptional activity of p53 is considered crucial for determining which p53 response is activated [5]. In this paper, we describe the expression of p53-related genes in the rat hippocampal CA1 area in the early phase of long-term potentiation $(30 \mathrm{~min}$ after tetanization) using real-time PCR. Our set of genes includes at least 50 genes that are transcriptionally regulated (directly or indirectly) by p53, as well as other p53-related genes, which are not known p53 transcriptional targets. The posttetanization time point was chosen from our previous data on the tetanization-induced increase in S100B mRNA, which is maximal at $30 \mathrm{~min}$ after tetanization $[3,14]$.

p53 transcriptional targets are regulated by multiple factors. One of the tools for the preliminary assessment of the transcription dependency on p53 is the inhibition of $\mathrm{Mdm} 2$ by nutlin-3 [15-17]. Mdm2 negatively modulates the transcriptional activity, the stability, and the mRNA translation of $\mathrm{p} 53$, and the inhibition of $\mathrm{Mdm} 2$ results in the activation of p53 and the increase in the p53 protein level $[13,18-20]$. Therefore, to estimate the contribution of $\mathrm{p} 53$ to the tetanization-induced regulation of the genes studied, we reexecuted our experiments using nutlin-3.

Although not definitive, our results allow hypothesizing that p53 participates in transcriptional regulation during the early phase of LTP. We hope that the presented data may aid in the understanding of the physiological function of p53related genes in the processes that are associated with synaptic plasticity.

\section{Materials and Methods}

2.1. Experimental Animals. Male Wistar rats (7-9 weeks of age) were supplied by the Institute of Cytology and Genetics SB RAS (Novosibirsk, Russia). Animals were acclimated for 1 week and were allowed free access to food and water. All experimental procedures were approved by the Animal Care Committee for the Institute of Molecular Biology and Biophysics SB RAMS and were performed in strict accordance with the National Institutes of Health guidelines.

2.2. Hippocampal Slice Preparation and Tetanization. Animals were decapitated, and the brain was rapidly removed and placed in ice-cold oxygenated $\left(95 \% \mathrm{O}_{2}, 5 \% \mathrm{CO}_{2}\right)$ artificial cerebrospinal fluid (ACSF): $126 \mathrm{mM} \mathrm{NaCl}, 4 \mathrm{mM} \mathrm{KCl}$,

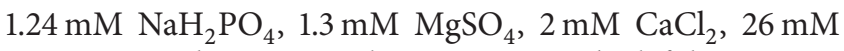
$\mathrm{NaHCO}_{3}$, and $10 \mathrm{mM}$ D-glucose, $\mathrm{pH}$ 7.4. The left hippocampus was dissected for removal and cut into $400 \mu \mathrm{m}$ thick transverse slices, using a chopper. Four consecutive slices from the dorsal region of the hippocampus were transferred to a submerged recording chamber. Slices were perfused at a rate of $2 \mathrm{~mL} / \mathrm{min}$ with fresh, oxygenated ACSF at room temperature $\left(22-24^{\circ} \mathrm{C}\right)$ for $30 \mathrm{~min}$; then the perfusion rate was reduced to $1.5 \mathrm{~mL} / \mathrm{min}$, and the temperature was raised to $32-33^{\circ} \mathrm{C}$. For extracellular recordings, the recording electrode, which was filled with ACSF, was placed in the CA1 pyramidal cell layer. To stimulate Schaffer collaterals, stimulating electrodes, which were filled with ACSF, were placed in the stratum radiatum. The intensity of the stimulation was adjusted to obtain a p-spike amplitude that was $\sim 50 \%$ of the maximal response.

P-spikes amplitudes were measured as the vertical distance from the peak of the spike to the line joining the peak positivities on either side. Slopes of field excitatory postsynaptic potentials were measured as the slope of the line joining the peak of the presynaptic volley and the peak positivity of the response.

Racemic nutlin-3 (Sigma-Aldrich) was dissolved in DMSO and stored at $-20^{\circ} \mathrm{C}$. Stock aliquots were dissolved in ACSF ex temporo. Slices were perfused with ACSF, which contained nutlin-3 $(20 \mu \mathrm{M})$ or vehicle (DMSO 0.1\%), from $30 \mathrm{~min}$ before to $30 \mathrm{~min}$ after the onset of tetanization.

In the experiments that were intended for the preparation of samples for real-time PCR and Western blot analysis, two of the four slices remained nonstimulated throughout the entire incubation period ( $4 \mathrm{~h} 15 \mathrm{~min}$ ) and were used as a baseline control in the corresponding set of samples. Two other slices were tetanized ( 4 trains of 1 s, $100 \mathrm{~Hz}$ stimulations spaced by $30 \mathrm{~s}$ intervals) $30 \mathrm{~min}$ before the termination of incubation. Electrodes were placed on the slices 2-5 min before the tetanization and were removed immediately after the stimulation. At the end of the incubation, slices were transferred to ice-cold oxygenated ACSF, and the CA1 field was rapidly cut away from each slice, as described previously [14], and placed into the Allprotect Tissue Reagent (Qiagen). Six relevant slices from three animals were pooled to prepare one mRNA/protein sample. Four independent tetanization/control pairs of samples were prepared for each (nutlin-3/vehicle) incubation condition.

2.3. cDNA Synthesis and Real-Time PCR. To identify the participation of p53 in transcriptional regulation during the early phase of LTP, a Rat p53 Signaling Pathway RT ${ }^{2}$ Profiler PCR Array (Qiagen) was used. Total RNA was isolated using an AllPrep DNA/RNA/Protein Mini Kit (Qiagen) according to manufacturer's protocol. The RNA concentration was measured using a Quant-iT Assay Kit and a Qubit instrument (Invitrogen); the RNA quality was evaluated by electrophoresis. cDNA was synthesized from total RNA using $\mathrm{RT}^{2}$ First Strand cDNA Synthesis Kit (Qiagen). Real-time PCR was performed with a Maxima SYBR Green qPCR Master Mix (Thermo Scientific) and a CFX96 Multicolor Detection System (Bio-Rad) according to manufacturer's 
instructions. The obtained data were analyzed using the Excel-based PCR Array Data Analysis Software (Qiagen). The mean of Ct values of five housekeeping genes (Actb, $\beta$-actin; B2m, beta- 2 microglobulin; Hprt1, hypoxanthine phosphoribosyltransferase 1; Ldha, lactate dehydrogenase A; Rplp1, ribosomal protein, large, P1) was used as the reference according to manufacturer's instructions. The concentration of S100B mRNA was measured as described previously [68].

2.4. Preparation of Whole-Cell Extracts. Whole-cell extracts from frozen slices were prepared using an AllPrep DNA/RNA/Protein Mini Kit (Qiagen) according to the manufacturer's protocol. Protein concentrations were determined using a Quant-iT Assay Kit and a Qubit instrument (Invitrogen).

2.5. SDS-PAGE Electrophoresis and Western Blot. Sixty micrograms of whole-cell proteins per lane was separated using 12\% SDS-PAGE and transferred to nitrocellulose membrane. Membranes were stained with Ponceau S to verify the loading and transfer efficiency. Immunodetection was performed using anti-p53 (1:500, Santa Cruz Biotechnology), anti-bax $(1: 2000)$, and anti-bcl $2(1: 1000, \mathrm{Abcam})$ or anti- $\beta$ actin $(1: 2000$, Sigma-Aldrich) antibodies. $\beta$-actin was used as a control to ensure the equal loading of samples. The bands were visualized using Visualizer Spray and a Glow ECL Western Blotting Detection System (Millipore).

2.6. Data Analysis. The data are expressed as the mean \pm S.E.M. The significance was assessed using Student's $t$-tests with the criterion set at $P<0.05$. In order to exclude the overestimation of the significance of studied genes mRNA fold changes due to possible inappropriate biases in values of housekeeping genes mRNAs, we performed the additional statistical analysis based on calculations made on the assumption that the expression of the housekeeping genes is constant. mRNA fold changes were considered as significant, if they were significant in both standard and additional tests. Besides, fold changes, which ranged from 0.95 to 1.05 , were considered as not significant.

\section{Results}

We used real-time PCR analysis to study the expression of 85 genes that are functionally related to p53 in the early phase of LTP in the CA1 area of rat hippocampal slices (Table 1). As described earlier [3, 69], our experimental protocol induces robust and enduring potentiation slightly reducing at $3 \mathrm{~h}$ after tetanization, which is characteristic of late-LTP produced in rat CA1 by repeated tetanization [70]. The application of vehicle (DMSO 0.1\%) in perfusing milieu from $30 \mathrm{~min}$ before to $30 \mathrm{~min}$ after tetanization did not influence significantly the basal responses (Figure 1), and the potentiation time course also did not differ significantly from that which has been previously described. Preliminary experiments showed that DMSO had no effect on basal expressions and tetanization-induced mRNA fold changes of genes studied (not presented).

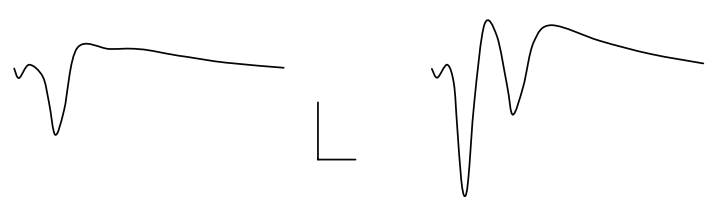

(a)

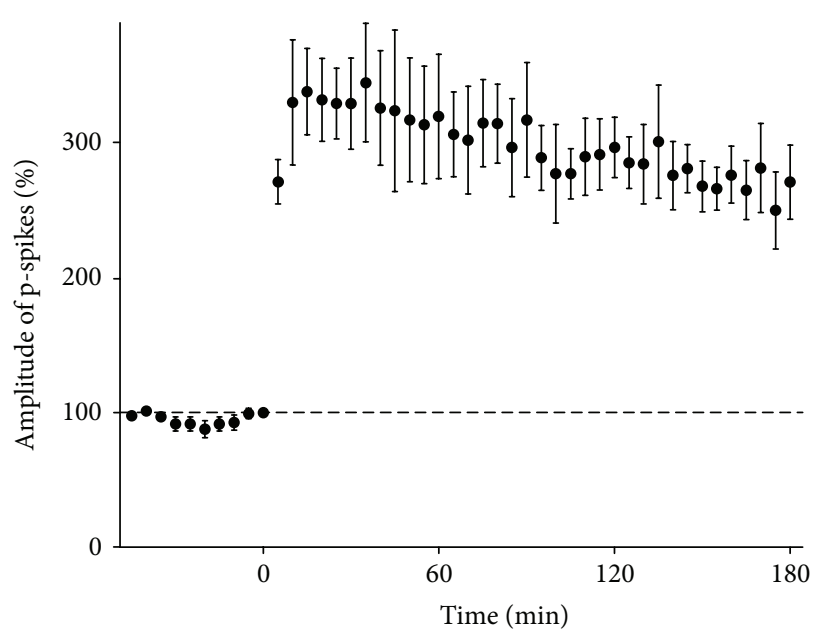

I Tetanization

- DMSO $0.1 \%$

(b)

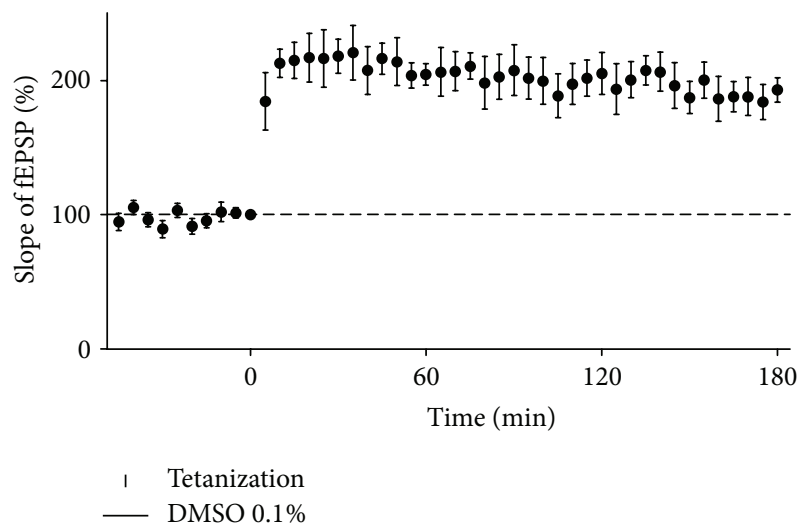

(c)

FIGURE 1: Long-term potentiation in the rat hippocampal CA1 area. (a) Representative responses to test stimuli before tetanization (left) and $30 \mathrm{~min}$ after tetanization (right). Calibration bars: $3 \mathrm{~ms}, 1 \mathrm{mV}$. (b, c) Abscissa, the time from the onset of tetanization. Ordinate, the amplitude of p-spikes (b) or the slope of field excitatory postsynaptic potentials (c), which is normalized to the amplitude of the response to the stimulus that immediately preceded tetanization. The data are the mean \pm S.E.M. $(n=4)$.

A short description of the genes studied is presented in Table 2. A variant of their functional classification is available on the PCR array manufacturer's website (http://www.sabiosciences.com/rt_pcr_product/HTML/PARN-027Z.html). Four transcripts (LOC367198, Myod1, Serpinb5, and Wt1) were not detected in our samples $(\mathrm{Ct}>35)$ and, therefore, were omitted in Table 1. Besides, Esrl, Lig4, Sfn, and Tnfrsf10b are not presented, since their changes were not significant in all the comparisons. 
TABLE 1: Expression of p53-related genes in rat hippocampal CA1 area $30 \mathrm{~min}$ after tetanization.

\begin{tabular}{|c|c|c|c|c|c|c|c|c|}
\hline \multirow{3}{*}{ Symbol } & \multicolumn{2}{|c|}{$\begin{array}{l}\text { p53 transcriptional } \\
\text { target genes }\end{array}$} & \multirow{2}{*}{\multicolumn{2}{|c|}{$\begin{array}{l}\text { Vehicle } \\
\text { Tetanization-induced } \\
\text { fold change }\end{array}$}} & \multicolumn{4}{|c|}{ Nutlin-3 } \\
\hline & \multirow[b]{2}{*}{ Regulation } & \multirow[b]{2}{*}{ Reference } & & & \multicolumn{2}{|c|}{$\begin{array}{l}\text { Basal expression } \\
\text { fold change }\end{array}$} & \multicolumn{2}{|c|}{$\begin{array}{l}\text { Tetanization-induced } \\
\text { fold change }\end{array}$} \\
\hline & & & TSv/CSv & $\begin{array}{l}\text { Paired } t \text {-test, } \\
\quad P<0.05\end{array}$ & $\mathrm{CSn} / \mathrm{CSv}$ & $\begin{array}{c}t \text {-test, } P< \\
0.05\end{array}$ & TSn/CSn & $\begin{array}{l}\text { Paired } t \text {-test, } \\
\quad P<0.05\end{array}$ \\
\hline Apaf1 & + & {$[21,22]$} & 1,25 & $*$ & 1,25 & $*$ & 1,25 & $*$ \\
\hline Apexl & & & 1,11 & $*$ & 1,29 & * & 0,98 & ns \\
\hline Atm & & & 1,27 & * & 1,37 & * & 1,08 & $*$ \\
\hline Bag1 & & & 1,13 & * & 1,30 & * & 1,01 & ns \\
\hline Bax & + & {$[23]$} & 1,41 & $*$ & 1,38 & * & 1,08 & ns \\
\hline $\mathrm{Bbc} 3$ & + & {$[24]$} & 0,93 & $*$ & 1,33 & $*$ & 0,87 & $*$ \\
\hline$B c l 2$ & - & [23] & 0,71 & * & 0,92 & * & 0,94 & ns \\
\hline Bid & + & {$[25]$} & 1,26 & $*$ & 1,23 & * & 1,19 & $*$ \\
\hline Birc5 & - & [26] & 1,22 & ns & 1,35 & * & 1,08 & ns \\
\hline Bnip3 & & & 1,13 & $*$ & 1,27 & $*$ & 1,08 & $*$ \\
\hline Brcal & - & [27] & 1,38 & $*$ & 1,58 & $*$ & 1,51 & ns \\
\hline Brca2 & & & 1,20 & * & 1,10 & * & 1,51 & $*$ \\
\hline Btg2 & + & [28] & 1,47 & * & 1,41 & * & 1,11 & $*$ \\
\hline Casp2 & & & 1,30 & * & 1,34 & * & 1,12 & $*$ \\
\hline Casp9 & & & 1,14 & $*$ & 1,28 & * & 1,02 & ns \\
\hline Ccnb1 & - & [29] & 1,03 & ns & 1,12 & * & 1,18 & $*$ \\
\hline Ccnel & & & 1,26 & $*$ & 1,31 & * & 1,10 & ns \\
\hline Ccng1 & + & {$[30]$} & 1,31 & * & 1,35 & $*$ & 1,16 & $*$ \\
\hline Ccnh & & & 1,18 & $*$ & 1,25 & $*$ & 1,11 & $*$ \\
\hline Cdc25a & - & {$[31]$} & 1,09 & ns & 1,06 & ns & 1,31 & $*$ \\
\hline $\mathrm{Cdc} 25 \mathrm{c}$ & - & {$[32]$} & 1,17 & ns & 1,13 & $*$ & 1,27 & $*$ \\
\hline Cdk1 & - & {$[33]$} & 0,96 & ns & 1,01 & ns & 1,31 & $*$ \\
\hline Cdk4 & & & 1,10 & $*$ & 1,24 & $*$ & 1,07 & $*$ \\
\hline Cdknla & + & {$[34]$} & 1,20 & $*$ & 1,17 & * & 1,15 & ns \\
\hline Cdkn2a & - & {$[35]$} & 1,06 & ns & 1,38 & * & 1,19 & ns \\
\hline Chek1 & - & [27] & 1,31 & $*$ & 1,29 & $*$ & 1,07 & ns \\
\hline Chek2 & - & [36] & 1,04 & ns & 1,22 & ns & 1,18 & $*$ \\
\hline Cul9 & & & 1,20 & ns & 1,35 & $*$ & 1,05 & ns \\
\hline Dapk1 & + & {$[37]$} & 1,34 & $*$ & 1,41 & $*$ & 0,90 & $*$ \\
\hline Dnmt1 & - & [38] & 1,15 & ns & 1,19 & ns & 1,16 & $*$ \\
\hline E2f1 & - & {$[17]$} & 1,34 & $*$ & 1,22 & $*$ & 1,28 & $*$ \\
\hline E2f3 & & & 1,62 & $*$ & 1,78 & * & 0,76 & $*$ \\
\hline Egfr & + & [39] & 1,39 & $*$ & 1,33 & * & 1,29 & $*$ \\
\hline Egr1 & + & {$[40]$} & 1,22 & $*$ & 1,21 & * & 1,11 & $*$ \\
\hline Ep300 & & & 1,17 & $*$ & 1,22 & $*$ & 1,02 & ns \\
\hline Erccl & & & 1,17 & $*$ & 1,29 & * & 1,11 & $*$ \\
\hline Fadd & & & 1,39 & $*$ & 1,57 & $*$ & 0,83 & $*$ \\
\hline Fas & + & {$[41,42]$} & 1,18 & ns & 1,14 & $*$ & 1,23 & ns \\
\hline Faslg & + & {$[43]$} & 1,19 & ns & 1,19 & * & 1,14 & $*$ \\
\hline Foxo3 & & & 1,49 & $*$ & 1,69 & * & 0,79 & $*$ \\
\hline Gadd45a & + & {$[44]$} & 1,26 & * & 1,41 & * & 0,96 & ns \\
\hline Hdacl & & & 1,12 & ns & 1,24 & * & 1,10 & ns \\
\hline Hifla & & & 1,30 & $*$ & 1,46 & $*$ & 0,95 & ns \\
\hline
\end{tabular}


TABLe 1: Continued.

\begin{tabular}{|c|c|c|c|c|c|c|c|c|}
\hline \multirow{3}{*}{ Symbol } & \multicolumn{2}{|c|}{$\begin{array}{l}\text { p53 transcriptional } \\
\text { target genes }\end{array}$} & \multicolumn{2}{|c|}{ Vehicle } & \multicolumn{4}{|c|}{ Nutlin-3 } \\
\hline & \multirow[b]{2}{*}{ Regulation } & \multirow[b]{2}{*}{ Reference } & \multicolumn{2}{|c|}{$\begin{array}{l}\text { Tetanization-induced } \\
\text { fold change }\end{array}$} & \multicolumn{2}{|c|}{$\begin{array}{l}\text { Basal expression } \\
\text { fold change }\end{array}$} & \multicolumn{2}{|c|}{$\begin{array}{l}\text { Tetanization-induced } \\
\text { fold change }\end{array}$} \\
\hline & & & $\mathrm{TSv} / \mathrm{CSv}$ & $\begin{array}{c}\text { Paired } t \text {-test, } \\
\quad P<0.05\end{array}$ & $\mathrm{CSn} / \mathrm{CSv}$ & $\begin{array}{c}t \text {-test, } P< \\
0.05\end{array}$ & $\mathrm{TSn} / \mathrm{CSn}$ & $\begin{array}{c}\text { Paired } t \text {-test, } \\
\quad P<0.05\end{array}$ \\
\hline Igflr & & & 1,08 & ns & 1,14 & * & 1,11 & * \\
\hline Il6 & - & {$[45]$} & 1,45 & $*$ & 1,31 & * & 1,26 & * \\
\hline Jun & & & 1,35 & $*$ & 1,32 & * & 1,15 & * \\
\hline Kras & & & 1,11 & ns & 1,22 & $*$ & 1,07 & ns \\
\hline Mcl1 & & & 1,30 & $*$ & 1,32 & * & 1,12 & $*$ \\
\hline$M d m 2$ & + & {$[46]$} & 1,21 & * & 1,22 & $*$ & 1,13 & ns \\
\hline Mdm4 & & & 1,16 & ns & 1,27 & * & 1,03 & ns \\
\hline Mlh1 & + & [47] & 1,16 & ns & 1,21 & * & 1,06 & ns \\
\hline Msh2 & + & {$[48]$} & 1,10 & ns & 1,11 & ns & 1,16 & $*$ \\
\hline Myc & - & [49] & 1,48 & $*$ & 1,31 & $*$ & 1,34 & $*$ \\
\hline Nf1 & & & 1,54 & $*$ & 1,25 & * & 1,37 & * \\
\hline Nfkb1 & & & 1,27 & $*$ & 1,27 & $*$ & 1,12 & $*$ \\
\hline Pcna & + & {$[50]$} & 1,33 & $*$ & 1,28 & * & 1,29 & * \\
\hline Pmaip1 & + & {$[51]$} & 1,55 & * & 1,47 & * & 1,16 & * \\
\hline Ppmld & + & {$[52]$} & 1,11 & $*$ & 1,23 & * & 1,10 & $*$ \\
\hline Prcl & - & {$[53]$} & 1,29 & ns & 1,28 & * & 1,20 & ns \\
\hline Prkca & - & {$[54]$} & 1,30 & $*$ & 0,92 & * & 1,58 & $*$ \\
\hline Pten & + & {$[55]$} & 1,47 & * & 1,46 & * & 0,92 & ns \\
\hline Pttg1 & - & {$[56]$} & 0,89 & $*$ & 0,96 & ns & 0,69 & $*$ \\
\hline Rb1 & - & {$[57]$} & 1,16 & ns & 1,30 & $*$ & 1,01 & ns \\
\hline Rela & & & 1,18 & $*$ & 1,31 & * & 0,99 & ns \\
\hline RGD1566319 & + & {$[58]$} & 1,23 & ns & 1,32 & $*$ & 1,04 & ns \\
\hline Rprm & + & [59] & 0,74 & $*$ & 0,95 & ns & 1,15 & $*$ \\
\hline S100B & + & {$[60]$} & 2,93 & $*$ & 1,51 & $*$ & 1,88 & $*$ \\
\hline Sirtl & & & 1,46 & $*$ & 1,32 & $*$ & 1,22 & $*$ \\
\hline Stat1 & & & 1,24 & $*$ & 1,36 & $*$ & 1,00 & ns \\
\hline $\operatorname{Tnf}$ & + & {$[61]$} & 1,28 & * & 1,25 & * & 1,13 & $*$ \\
\hline Tp53 & + & {$[40,62]$} & 1,00 & ns & 1,17 & ns & 1,07 & $*$ \\
\hline Tp53bp2 & - & {$[63]$} & 1,11 & $*$ & 1,13 & $*$ & 1,06 & ns \\
\hline Tp63 & + & {$[64]$} & 1,17 & ns & 0,98 & ns & 1,39 & $*$ \\
\hline Tp73 & + & {$[40,65,66]$} & 2,15 & $*$ & 1,43 & * & 1,76 & $*$ \\
\hline Xrcc4 & & & 1,03 & ns & 1,14 & * & 1,15 & $*$ \\
\hline Xrcc5 & & & 1,35 & ns & 1,40 & * & 1,10 & ns \\
\hline Zmat3 & + & {$[67]$} & 0,99 & ns & 1,06 & ns & 1,22 & $*$ \\
\hline
\end{tabular}

TSv, CSv, TSn, CSn: test and control samples from experiments with vehicle (DMSO 0.1\%) or nutlin-3 (20 $\mu \mathrm{M})$. Tetanization-induced fold changes (TSv/CSv and TSn/CSn) were expressed by taking the value of the corresponding control as one. Basal expression fold change (CSn/CSv) was expressed by taking average value of the group CSv as one. Italic marks symbols of the genes, which are regulated similarly by tetanization and nutlin, and effect of tetanization is occluded by nutlin. ${ }^{*} P<0.05(n=4)$, ns: not significant.

The tetanization-induced changes in expression profiles of genes that are upregulated (p53-URG) or downregulated by p53 (p53-DRG) did not differ significantly. Specifically, the expression of only two p53-DRGs (11\%), Bcl2 and Pttg1, significantly decreased, whereas the expression of seven p53-DRGs (37\%) significantly increased after tetanization.
Similarly, the expression of two p53-URGs (6\%), Bbc3/Puma and Rprm, also decreased, whereas the expression of 18 p53URGs (58\%) increased after tetanization. Thus, the LTPrelated regulation of $\mathrm{p} 53$ transcriptional target genes appears to be rather complex, and the contribution of p53 to this regulation seems to not be crucial, in many instances. 
TABLE 2: Description of p53-related genes.

\begin{tabular}{|c|c|c|c|}
\hline RefSeq & Symbol & Description & Gene name \\
\hline NM_023979 & Apaf1 & Apoptotic peptidase activating factor 1 & - \\
\hline NM_024148 & Apex1 & APEX nuclease (multifunctional DNA repair enzyme) 1 & APE, Apex, REF-1 \\
\hline NM_001106821 & Atm & Ataxia telangiectasia mutated homolog (human) & - \\
\hline NM_001106647 & Bag1 & BCL2-associated athanogene & - \\
\hline NM_017059 & Bax & Bcl2-associated X protein & - \\
\hline NM_173837 & $\mathrm{Bbc} 3$ & Bcl-2 binding component 3 & Puma \\
\hline NM_016993 & $\mathrm{Bcl} 2$ & B-cell CLL/lymphoma 2 & Bcl-2 \\
\hline NM_022684 & Bid & $\mathrm{BH} 3$ interacting domain death agonist & - \\
\hline NM_022274 & Birc5 & Baculoviral IAP repeat-containing 5 & AP14 \\
\hline NM_053420 & Bnip3 & BCL2/adenovirus E1B interacting protein 3 & MGC93043 \\
\hline NM_012514 & Brcal & Breast cancer 1 & - \\
\hline NM_031542 & Brca2 & Breast cancer 2 & - \\
\hline NM_017259 & Btg2 & BTG family, member 2 & $\begin{array}{l}\text { Agl, An, Pc3, Tis21, } \\
\text { an-1 }\end{array}$ \\
\hline NM_022522 & Casp2 & Caspase 2 & - \\
\hline NM_031632 & Casp9 & Caspase 9, apoptosis-related cysteine peptidase & $\begin{array}{c}\text { Apaf3, Casp-9-CTD, } \\
\text { Casp9_vl, Ice-Lap6, } \\
\text { Mch6 }\end{array}$ \\
\hline NM_171991 & Ccnb1 & Cyclin B1 & - \\
\hline NM_001100821 & Ccnel & Cyclin E1 & CYCLE, Ccne \\
\hline NM_012923 & Ccng1 & Cyclin G1 & $\begin{array}{l}\text { CYCG, Ccng, } \\
\text { MGC93642 }\end{array}$ \\
\hline NM_052981 & Ccnh & Cyclin $\mathrm{H}$ & - \\
\hline NM_133571 & Cdc25a & Cell division cycle 25 homolog A (S. pombe) & - \\
\hline NM_001107396 & $\mathrm{Cdc} 25 \mathrm{c}$ & Cell division cycle 25 homolog C (S. pombe) & - \\
\hline NM_019296 & Cdk1 & Cyclin-dependent kinase 1 & $\mathrm{Cdc} 2, \mathrm{Cdc} 2 \mathrm{a}$ \\
\hline NM_053593 & $\mathrm{Cdk} 4$ & Cyclin-dependent kinase 4 & - \\
\hline NM_080782 & Cdknla & Cyclin-dependent kinase inhibitor $1 \mathrm{~A}$ & Cip1, Waf1 \\
\hline NM_031550 & Cdkn2a & Cyclin-dependent kinase inhibitor $2 \mathrm{~A}$ & $\begin{array}{l}\text { Arf, INK4A, MTS1, } \\
\text { p16, p16Cdkn2a, } \\
\text { p19ARF }\end{array}$ \\
\hline NM_080400 & Chek1 & CHK1 checkpoint homolog (S. pombe) & - \\
\hline NM_053677 & Chek2 & CHK2 checkpoint homolog (S. pombe) & Chk2, Rad53 \\
\hline XM_236927 & Cul9 & Cullin 9 & Parc, RGD1562008 \\
\hline NM_001107335 & Dapk1 & Death associated protein kinase 1 & - \\
\hline NM_053354 & Dnmt1 & DNA (cytosine-5-)-methyltransferase 1 & - \\
\hline NM_001100778 & E2f1 & E2F transcription factor 1 & - \\
\hline NM_001137626 & $\mathrm{E} 2 \mathrm{f} 3$ & E2F transcription factor 3 & RGD1561600 \\
\hline NM_031507 & Egfr & Epidermal growth factor receptor & ERBB1, ErbB-1, Errp \\
\hline NM_012551 & Egr1 & Early growth response 1 & $\begin{array}{l}\text { Krox-24, NGFI-A, } \\
\text { Ngf1, Ngfi, zif- } 268\end{array}$ \\
\hline XM_576312 & Ep300 & E1A binding protein $\mathrm{p} 300$ & - \\
\hline NM_001106228 & Erccl & $\begin{array}{l}\text { Excision repair cross-complementing rodent repair deficiency, } \\
\text { complementation group } 1\end{array}$ & - \\
\hline NM_012689 & Esrl & Estrogen receptor 1 & $\begin{array}{l}\text { ER-alpha, Esr, } \\
\text { RNESTROR }\end{array}$ \\
\hline NM_152937 & Fadd & Fas (TNFRSF6) associated via death domain & Mort1 \\
\hline NM_139194 & Fas & Fas (TNF receptor superfamily, member 6) & Tnfrsf6 \\
\hline NM_012908 & Faslg & Fas ligand (TNF superfamily, member 6) & $\begin{array}{l}\text { Apt1Lg1, CD95-L, } \\
\text { Fasl, Tnfsf6 }\end{array}$ \\
\hline
\end{tabular}


TABLE 2: Continued.

\begin{tabular}{|c|c|c|c|}
\hline RefSeq & Symbol & Description & Gene name \\
\hline NM_001106395 & Foxo3 & Forkhead box O3 & Fkhrl1, Foxo3a \\
\hline NM_024127 & Gadd45a & Growth arrest and DNA-damage-inducible, alpha & Dditl, Gadd45 \\
\hline NM_001025409 & Hdacl & Histone deacetylase 1 & - \\
\hline NM_024359 & Hifla & $\begin{array}{l}\text { Hypoxia-inducible factor 1, alpha subunit (basic helix-loop-helix transcription } \\
\text { factor) }\end{array}$ & MOP1 \\
\hline NM_052807 & Igflr & Insulin-like growth factor 1 receptor & IGFIRC, JTK13 \\
\hline NM_012589 & Il6 & Interleukin 6 & ILg6, Ifnb2 \\
\hline NM_021835 & Jun & Jun oncogene & - \\
\hline NM_031515 & Kras & V-Ki-ras2 Kirsten rat sarcoma viral oncogene homolog & Kras2, c-Ki-ras, p21 \\
\hline NM_001106095 & Lig4 & Ligase IV, DNA, ATP-dependent & - \\
\hline XM_346005 & LOC367198 & $\begin{array}{l}\text { Similar to Serine/threonine-protein kinase ATR (Ataxia telangiectasia and } \\
\text { Rad3-related protein) }\end{array}$ & - \\
\hline NM_021846 & Mcll & Myeloid cell leukemia sequence 1 & - \\
\hline NM_001108099 & $\mathrm{Mdm} 2$ & Mdm2 p53 binding protein homolog (mouse) & - \\
\hline NM_001012026 & Mdm4 & Mdm4 p53 binding protein homolog (mouse) & - \\
\hline NM_031053 & Mlh1 & MutL homolog 1 (E. coli) & - \\
\hline NM_031058 & Msh2 & MutS homolog 2 (E. coli) & - \\
\hline NM_012603 & Myc & Myelocytomatosis oncogene & $\begin{array}{c}\text { MGC105490, } \\
\text { RNCMYC, c-myc, } \\
\text { mMyc }\end{array}$ \\
\hline NM_176079 & Myod1 & Myogenic differentiation 1 & MGC156574 \\
\hline NM_012609 & Nf1 & Neurofibromin 1 & - \\
\hline XM_342346 & Nfkbl & Nuclear factor of kappa light polypeptide gene enhancer in B-cells 1 & NF-kB \\
\hline NM_022381 & Pcna & Proliferating cell nuclear antigen & PCNAR, Pcna, cyclin \\
\hline NM_001008385 & Pmaip1 & Phorbol-12-myristate-13-acetate-induced protein 1 & Noxa \\
\hline NM_001105825 & Ppmld & Protein phosphatase 1D magnesium-dependent, delta isoform & - \\
\hline NM_001107529 & Prcl & Protein regulator of cytokinesis 1 & - \\
\hline NM_001105713 & Prkca & Protein kinase C, alpha & Pkca \\
\hline NM_031606 & Pten & Phosphatase and tensin homolog & $\begin{array}{l}\text { MMAC1, Mmac, } \\
\text { TEP1 }\end{array}$ \\
\hline NM_022391 & Pttg1 & Pituitary tumor-transforming 1 & Pttg \\
\hline NM_017045 & $\mathrm{Rb} 1$ & Retinoblastoma 1 & - \\
\hline NM_199267 & Rela & V-rel reticuloendotheliosis viral oncogene homolog A (avian) & NFkB \\
\hline NM_001109358 & RGD1566319 & Similar to Sestrin 2 (Hi95) & - \\
\hline NM_001044276 & Rprm & Reprimo, TP53 dependent G2 arrest mediator candidate & MGC109515 \\
\hline NM_013191 & S100B & S100 calcium binding protein $B$ & - \\
\hline NM_057108 & Serpinb5 & Serpin peptidase inhibitor, clade B (ovalbumin), member 5 & Maspin, PI-5, Pi5 \\
\hline XM_232745 & Sfn & Stratifin & - \\
\hline NM_001107627 & Sirtl & Sirtuin (silent mating type information regulation 2 homolog) 1 (S. cerevisiae) & Sir2 \\
\hline NM_032612 & Stat1 & Signal transducer and activator of transcription 1 & - \\
\hline NM_012675 & Tnf & Tumor necrosis factor (TNF superfamily, member 2) & $\begin{array}{c}\text { MGC124630, } \\
\text { RATTNF, TNF-alpha, } \\
\text { Tnfa }\end{array}$ \\
\hline NM_001108873 & Tnfrsflob & Tumor necrosis factor receptor superfamily, member $10 \mathrm{~b}$ & - \\
\hline NM_030989 & $\operatorname{Tp} 53$ & Tumor protein $\mathrm{p} 53$ & $\begin{array}{l}\text { MGC112612, Trp53, } \\
\text { p53 }\end{array}$ \\
\hline XM_223012 & Tp53bp2 & Tumor protein p53 binding protein, 2 & Trp53bp2 \\
\hline NM_019221 & Tp63 & Tumor protein p63 & $\begin{array}{l}\text { Ket, } \mathrm{P731}, \mathrm{Tp} 731 \text {, } \\
\text { Trp63 }\end{array}$ \\
\hline NM_001108696 & $\mathrm{Tp} 73$ & Tumor protein $\mathrm{p} 73$ & P73, Trp73 \\
\hline
\end{tabular}


TABLE 2: Continued.

\begin{tabular}{lclc}
\hline RefSeq & Symbol & Description & Gene name \\
\hline NM_031534 & Wt1 & Wilms tumor 1 & - \\
NM_001006999 & Xrcc4 & X-ray repair complementing defective repair in Chinese hamster cells 4 & MGC95022 \\
NM_177419 & Xrcc5 & X-ray repair complementing defective repair in Chinese hamster cells 5 & Ku80, Kup80 \\
NM_022548 & Zmat3 & Zinc finger, matrin type 3 & PAG608, Wig1 \\
\hline
\end{tabular}

To estimate the possible contribution of p53 to the regulation of tetanization-induced gene expression, we inhibited Mdm2 by nutlin-3. Surprisingly, nutlin-3 attenuated basal mRNA levels of only a few p53-DRGs (Bcl2, Prkca, and Pttg1), whereas the expression of most genes increased (Table 1), which partly might be associated with the involvement of $\mathrm{Mdm} 2$ in the regulation of mRNA stability [71].

We assumed that necessary (but not sufficient) criteria for a gene, which is regulated predominantly by p53 after tetanization, are (1) the level of mRNA changes significantly after tetanization under normal conditions; (2) nutlin significantly shifts the basal expression in the same direction as tetanization; and (3) in the presence of nutlin, the effect of tetanization is not significant. We found 16 genes, which conformed to these criteria (Table 1). Six of them (Bax, Bcl2, Cdknla, Gadd45a, Mdm2, and Pten) are known p53 target genes and, therefore, might be considered as promising candidates for more detailed studies of the possible involvement of p53 in the tetanization-induced transcriptional regulation. We chose two of these genes, proapoptotic Bax and antiapoptotic $\mathrm{Bcl} 2$, that are up- and downregulated by $\mathrm{p} 53$, respectively, to confirm the changes in their expression on the protein level. Indeed, $\mathrm{Bax}$ and $\mathrm{Bcl} 2$ protein contents followed changes in the mRNA contents (Figure 2).

Consistent with previous results [3], the induction of LTP was accompanied by a decrease in the protein level of p53 (Figures 2(b) and 2(c)). Nutlin-3 increased the average basal p53 protein level and completely blocked its tetanizationinduced depletion (Figures 2(b) and 2(c)). This effect seemed to be associated not only with the inhibition of the Mdm2dependent degradation of p53 but also with its augmented synthesis due to elevated levels of p53 mRNA (Figure 2(a), Table 1).

\section{Discussion}

In spite of the remarkable achievements of many researchers in the identification of LTP-related genes, the extremely complex transcriptional program that is activated in neuroglial networks during LTP remains poorly understood. Our previous results [3] suggest that LTP in the hippocampal CA1 area is accompanied by a transient increase in the transcriptional activity of p53. However, we could find only a few reported examples of p53 target genes that are transcriptionally regulated during the early phase of hippocampal LTP and only in the dentate gyrus [72-75]. Hippocampal subregions differ one from another in their gene expression profiles [76]. Besides, gene expression differences across the septotemporal (dorsal-ventral) axis of the hippocampus within CA1 were demonstrated [77], and the induction of LTP is differently regulated in dorsal hippocampus versus ventral hippocampus [78]. Therefore, we studied the expression of p53-related genes in the early phase of LTP in the rat dorsal hippocampal CA1 area using real-time PCR analysis. Our set of genes was composed of at least 50 genes that are transcriptionally regulated by p53 (directly or indirectly), as well as other genes that are related to p53-dependent processes (Tables 1 and 2).

To evaluate the contribution of p53 to tetanizationinduced expression profile changes, we inhibited the primary negative regulator of $\mathrm{p} 53 \mathrm{Mdm} 2$ by nutlin-3. Mdm2 negatively modulates (partly independently) the transcriptional activity, the stability, and the mRNA translation of p53, and the inhibition of $\mathrm{Mdm} 2$ by nutlin results in both the increase in 553 protein level and the activation of p53-dependent transcription [15]. Therefore, we measured the protein level of p53 to assess the effectiveness of nutlin-3 under our experimental conditions. We observed the significant increase in the protein level of p53 in the presence of nutlin-3, which suggested the effective inhibition of $\mathrm{Mdm} 2$ and, therefore, the transcriptional activation of p53. However, because Mdm2 may also influence the transcription of p53 targets through p53independent pathways $[20,71]$, the results that were obtained using nutlin-3 are only circumstantial and are not definitive.

When LTP is induced, the activity of p53 cannot correlate with its total protein amount [3], which is not amazing. The activity of p53 is regulated by numerous mechanisms $[5,79]$, and the induction of LTP is associated with the activation of multiple regulatory cascades $[1,2,80]$, which might influence the portion of the activated p53, its localization, and the recruitment of cofactors.

We observed the upregulation of numerous p 53 targets, as well as other p53-related genes, at $30 \mathrm{~min}$ after tetanization. However, a percentage of the upregulated genes in the p53URG group insignificantly exceeded that in the p53-DRG group. Therefore, it is evident, for p53-DRGs and, by analogy, extremely likely for p53-URGs, that p53 is not a single mediator of their LTP-associated regulation. The p53 homologue p73 represents an example of such a complex regulation. Tp73 is one of the genes that are upregulated the most after tetanization in our samples. However, this gene can be upregulated not only by $\mathrm{p} 53$ but also by p73 itself and by Egr1 [40]. Nutlin-3 only partly simulated the tetanization-induced upregulation of Tp73 and did not effectively occlude the effect of tetanization (Table 1), which suggests the relatively small involvement of p53 in tetanization-induced upregulation of Tp73.

Egrl is an immediate early gene, which appears to be critical for memory formation and LTP maintenance [2]. However, in response to stress, Egrl displays a remarkable 

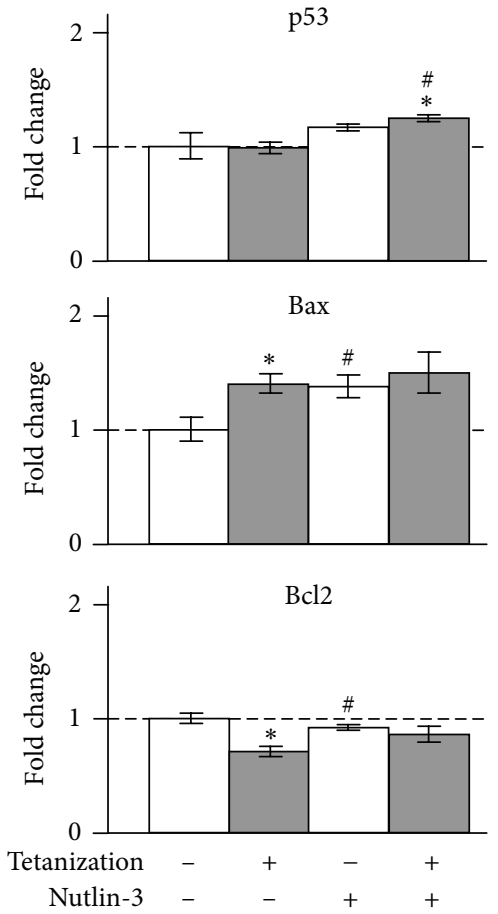

(a)
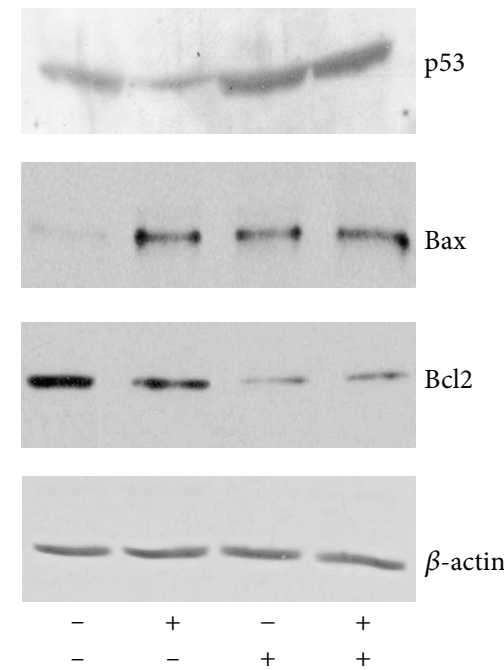

(b)
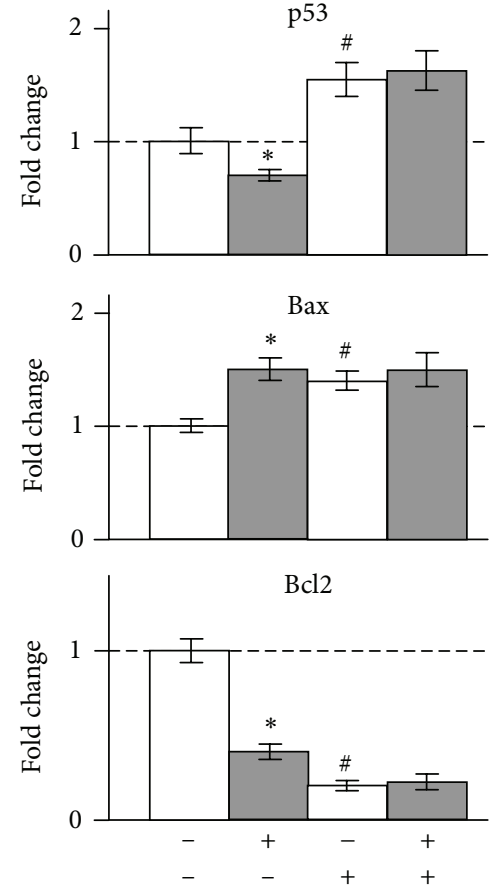

(c)

FIGURE 2: Effect of tetanization on p53, Bax, and Bcl2 in the rat hippocampal CA1 area. (a) Total RNAs were prepared and subjected to realtime PCR for the measurement of mRNAs. The mean of Ct values of five housekeeping genes was used as internal control for normalization as described in Section 2. (b) Representative Western blots. Whole-cell extracts were prepared from the rat hippocampal CA1 area and subjected to Western blot analysis as described in Section 2. (c) Relative intensity. The protein bands were analyzed by the computerized densitometric program "Total Lab." The intensities of the signals were determined from the areas under the curves for each peak and data were graphed. $\beta$-actin was used as internal control for normalization. The fold changes were expressed by taking the average value of the group tetanization ${ }^{(-)} /$nutlin- $3^{(-)}$as one. ${ }^{*} P<0.05$ against corresponding tetanization ${ }^{(-)}$samples (paired $t$-test), ${ }^{\#} P<0.05$ against the group tetanization ${ }^{(-)} /$nutlin- $3^{(-)}(t$-test $), n=4$.

functional similarity to 53 and p73 [81-84]. Egrl target genes overlap those genes of p53. Egrl, p73, and p53 form a network with positive feedback loops, which respond to stress by the prolonged expression of the p53 family of genes, which results in efficient apoptosis [40]. Our results indicate that the activation of this network is strongly restricted during LTP by Mdm2 activity. Specifically, the induction of LTP was followed by a decrease in the p53 protein level, whereas the p53 mRNA level did not change. However, when Mdm2 was inhibited by nutlin-3 not only was the p53 protein level rescued but also p53 mRNA increased at $30 \mathrm{~min}$ after tetanization. Thus, Mdm2 seems to effectively attenuate the activity of the Egrl-p73-p53 network during LTP, which might be explained by the capability of Mdm2 to suppress the transcriptional function of both p53 and p73 [85].

\section{Conclusion}

Thus, during the formation of LTP in the hippocampal CA1 area, the increase in the transcriptional activity of p53 seems to occur under tight constraints and leads to the selective transcriptional regulation of target genes. The induction of LTP entails the transcriptional upregulation and/or posttranslational activation of negative regulators of p53 (such as Mdm2), which lead to a rapid cessation of p53 activity. Moreover, in some instances, p53 activity is overridden by other neuron activity-dependent transcriptional regulators. The definite functional roles of p53 and related factors in tetanization-induced processes remain to be elucidated, and now the relevance of these factors to excitotoxicity or to abnormal in vitro conditions cannot be excluded. Nevertheless, it is possible that p53-dependent transcriptional program may be an essential part of synaptic activity-driven adaptive processes. Our results may help to understand the physiological function of p53 pathway in the processes associated with synaptic plasticity. However, to further corroborate the functional significance of p53 in transcriptional regulation during LTP, more detailed studies should be performed using chromatin immunoprecipitation, p53-knockdown or mRNA interference models, promoter constructs, and immunohistochemistry.

\section{Conflict of Interests}

The authors declare that there is no conflict of interests regarding the publication of this paper. 


\section{Authors' Contribution}

Vladimir O. Pustylnyak and Pavel D. Lisachev contributed equally to this work.

\section{Acknowledgments}

This study was partially supported by the Russian Foundation for Basic Research (Grants nos. 12-04-00464-a and 15-0401753-a), the Russian Science Foundation (Project no. 14-3500020 to Vladimir O. Pustylnyak), and basic research project of the Russian Academy of Sciences (IV.35.1.5).

\section{References}

[1] K. G. Reymann and J. U. Frey, "The late maintenance of hippocampal LTP: requirements, phases, 'synaptic tagging', 'late-associativity' and implications," Neuropharmacology, vol. 52, no. 1, pp. 24-40, 2007.

[2] C. M. Alberini, "Transcription factors in long-term memory and synaptic plasticity," Physiological Reviews, vol. 89, no. 1, pp. 121-145, 2009.

[3] V. O. Pustylnyak, P. D. Lisachev, M. B. Shtark, and O. I. Epstein, "Regulation of S100B gene in rat hippocampal CA1 area during long term potentiation," Brain Research, vol. 1394, pp. 33-39, 2011.

[4] O. Laptenko and C. Prives, "Transcriptional regulation by p53: one protein, many possibilities," Cell Death and Differentiation, vol. 13, no. 6, pp. 951-961, 2006.

[5] K. H. Vousden and C. Prives, "Blinded by the Light: the growing complexity of p53," Cell, vol. 137, no. 3, pp. 413-431, 2009.

[6] K. Kuribayashi and W. S. El-Deiry, "Regulation of programmed cell death by the p53 pathway," Advances in Experimental Medicine and Biology, vol. 615, pp. 201-221, 2008.

[7] A. Tedeschi and S. Di Giovanni, "The non-apoptotic role of p53 in neuronal biology: enlightening the dark side of the moon," The EMBO Reports, vol. 10, no. 6, pp. 576-583, 2009.

[8] S. Solá, M. M. Aranha, and C. M. P. Rodrigues, "Driving apoptosis-relevant proteins toward neural differentiation," Molecular Neurobiology, vol. 46, no. 2, pp. 316-331, 2012.

[9] Z. Li, J. Jo, J. M. Jia et al., "Caspase-3 activation via mitochondria is required for long-term depression and AMPA receptor internalization," Cell, vol. 141, no. 5, pp. 859-871, 2010.

[10] N. V. Gulyaeva, I. E. Kudryashov, and I. V. Kudryashova, "Caspase activity is essential for long-term potentiation," Journal of Neuroscience Research, vol. 73, no. 6, pp. 853-864, 2003.

[11] M. Agostini, P. Tucci, J. R. Steinert et al., "microRNA-34a regulates neurite outgrowth, spinal morphology, and function," Proceedings of the National Academy of Sciences of the United States of America, vol. 108, no. 52, pp. 21099-21104, 2011.

[12] H. Nishiyama, T. Knöpfel, S. Endo, and S. Itohara, "Glial protein S100B modulates long-term neuronal synaptic plasticity," Proceedings of the National Academy of Sciences of the United States of America, vol. 99, no. 6, pp. 4037-4042, 2002.

[13] J. McAfoose and B. T. Baune, "Evidence for a cytokine model of cognitive function," Neuroscience and Biobehavioral Reviews, vol. 33, no. 3, pp. 355-366, 2009.

[14] P. D. Lisachev, M. B. Shtark, O. O. Sokolova, V. O. Pustylnyak, M. Y. Salakhutdinova, and O. I. Epstein, "A comparison of the dynamics of S100B, S100A1, and S100A6 mRNA expression in
Hippocampal CA1 area of rats during long-term potentiation and after low-frequency stimulation," Cardiovascular Psychiatry and Neurology, vol. 2010, Article ID 720958, 6 pages, 2010.

[15] L. T. Vassilev, B. T. Vu, B. Graves et al., "In vivo activation of the p53 pathway by small-molecule antagonists of MDM2," Science, vol. 303 , no. 5659, pp. 844-848, 2004.

[16] B. Huang and L. T. Vassilev, "Reduced transcriptional activity in the p53 pathway of senescent cells revealed by the MDM2 antagonist nutlin-3," Aging, vol. 1, no. 10, pp. 845-854, 2009.

[17] L. A. Carvajal, P.-J. Hamard, C. Tonnessen, and J. J. Manfredi, "E2F7, a novel target, is up-regulated by p53 and mediates DNA damage-dependent transcriptional repression," Genes \& Development, vol. 26, no. 14, pp. 1533-1545, 2012.

[18] D. Michael and M. Oren, "The p53-Mdm2 module and the ubiquitin system," Seminars in Cancer Biology, vol. 13, no. 1, pp. 49-58, 2003.

[19] Y. Ofir-Rosenfeld, K. Boggs, D. Michael, M. B. Kastan, and M. Oren, "Mdm2 regulates p53 mRNA translation through inhibitory interactions with ribosomal protein L26," Molecular Cell, vol. 32, no. 2, pp. 180-189, 2008.

[20] S. Nag, J. Qin, K. S. Srivenugopal, M. Wang, and R. Zhang, "The MDM2-p53 pathway revisited," Journal of Biomedical Research, vol. 27, no. 4, pp. 254-271, 2013.

[21] M. C. Moroni, E. S. Hickman, E. L. Denchi et al., "Apaf-1 is a transcriptional target for E2F and p53," Nature Cell Biology, vol. 3, no. 6, pp. 552-558, 2001.

[22] A. I. Robles, N. A. Bemmels, A. B. Foraker, and C. C. Harris, "APAF-1 is a transcriptional target of p53 in DNA damageinduced apoptosis," Cancer Research, vol. 61, no. 18, pp. 6660$6664,2001$.

[23] T. Miyashita, S. Krajewski, M. Krajewska et al., "Tumor suppressor $\mathrm{p} 53$ is a regulator of bcl-2 and bax gene expression in vitro and in vivo," Oncogene, vol. 9, no. 6, pp. 1799-1805, 1994.

[24] K. Nakano and K. H. Vousden, "PUMA, a novel proapoptotic gene, is induced by p53," Molecular Cell, vol. 7, no. 3, pp. 683694, 2001.

[25] J. K. Sax, P. Fei, M. E. Murphy, E. Bernhard, S. J. Korsmeyer, and W. S. El-Deiry, "BID regulation by p53 contributes to chemosensitivity," Nature Cell Biology, vol. 4, no. 11, pp. 842849, 2002.

[26] W. H. Hoffman, S. Biade, J. T. Zilfou, J. Chen, and M. Murphy, "Transcriptional repression of the anti-apoptotic survivin gene by wild type p53," The Journal of Biological Chemistry, vol. 277, no. 5, pp. 3247-3257, 2002.

[27] K. Löhr, C. Möritz, A. Contente, and M. Dobbelstein, "p21/CDKN1A mediates negative regulation of transcription by p53," The Journal of Biological Chemistry, vol. 278, no. 35, pp. 32507-32516, 2003.

[28] J.-P. Rouault, N. Falette, F. Guehenneux et al., "Identification of BTG2, an antiproliferative p53-dependent component of the DNA damage cellular response pathway," Nature Genetics, vol. 14 , no. 4 , pp. $482-486,1996$.

[29] S. A. Innocente, J. L. A. Abrahamson, J. P. Cogswell, and J. M. Lee, "p53 regulates a $G_{2}$ checkpoint through cyclin B1," Proceedings of the National Academy of Sciences of the United States of America, vol. 96, no. 5, pp. 2147-2152, 1999.

[30] K. Okamoto and D. Beach, "Cyclin G is a transcriptional target of the p53 tumor suppressor protein," The EMBO Journal, vol. 13, no. 20, pp. 4816-4822, 1994.

[31] K. Rother, R. Kirschner, K. Sänger, L. Böhlig, J. Mössner, and K. Engeland, "p53 downregulates expression of the G1/S cell cycle 
phosphatase Cdc25A," Oncogene, vol. 26, no. 13, pp. 1949-1953, 2007.

[32] S. S. Clair, L. Giono, S. Varmeh-Ziaie et al., "DNA damageinduced downregulation of $\mathrm{Cdc} 25 \mathrm{C}$ is mediated by $\mathrm{p} 53$ via two independent mechanisms: one involves direct binding to the cdc25C promoter," Molecular Cell, vol. 16, no. 5, pp. 725-736, 2004.

[33] C. Badie, J. E. Itzhaki, M. J. Sullivan, A. J. Carpenter, and A. C. G. Porter, "Repression of CDK1 and other genes with CDE and CHR promoter elements during DNA damage-induced G2/M arrest in human cells," Molecular and Cellular Biology, vol. 20, no. 7, pp. 2358-2366, 2000.

[34] W. S. El-Deiry, T. Tokino, T. Waldman et al., "Topological control of p21WAF1/CIP1 expression in normal and neoplastic tissues," Cancer Research, vol. 55, no. 13, pp. 2910-2919, 1995.

[35] F. J. Stott, S. Bates, M. C. James et al., "The alternative product from the human CDKN2A locus, p14(ARF), participates in a regulatory feedback loop with p53 and MDM2," The EMBO Journal, vol. 17, no. 17, pp. 5001-5014, 1998.

[36] T. Matsui, Y. Katsuno, T. Inoue et al., "Negative regulation of Chk2 expression by $\mathrm{p} 53$ is dependent on the CCAAT-binding transcription factor NF-Y," The Journal of Biological Chemistry, vol. 279, no. 24, pp. 25093-25100, 2004.

[37] A. Martoriati, G. Doumont, M. Alcalay, E. Bellefroid, P. G. Pelicci, and J.-C. Marine, "Dapk1, encoding an activator of a p19 ${ }^{A R F}$-p53-mediated apoptotic checkpoint, is a transcription target of p53," Oncogene, vol. 24, no. 8, pp. 1461-1466, 2005.

[38] E. J. Peterson, O. Bögler, and S. M. Taylor, "p53-mediated repression of DNA methyltransferase 1 expression by specific DNA binding," Cancer Research, vol. 63, no. 20, pp. 6579-6582, 2003.

[39] J. H. Ludes-Meyers, M. A. Subler, C. V. Shivakumar et al., "Transcriptional activation of the human epidermal growth factor receptor promoter by human p53," Molecular and Cellular Biology, vol. 16, no. 11, pp. 6009-6019, 1996.

[40] J. Yu, V. Baron, D. Mercola, T. Mustelin, and E. D. Adamson, "A network of p73, p53 and Egrl is required for efficient apoptosis in tumor cells," Cell Death and Differentiation, vol. 14, no. 3, pp. 436-446, 2007.

[41] L. B. Owen-Schaub, W. Zhang, J. C. Cusack et al., "Wildtype human p53 and a temperature-sensitive mutant induce Fas/APO-1 expression," Molecular and Cellular Biology, vol. 15, no. 6, pp. 3032-3040, 1995.

[42] M. Müller, S. Wilder, D. Bannasch et al., "p53 activates the CD95 (APO-1/Fas) gene in response to DNA damage by anticancer drugs," The Journal of Experimental Medicine, vol. 188, no. 11, pp. 2033-2045, 1998.

[43] T. Fukazawa, T. Fujiwara, Y. Morimoto et al., "Differential involvement of the CD95 (Fas/APO-1) receptor/ligand system on apoptosis induced by the wild-type p53 gene transfer in human cancer cells," Oncogene, vol. 18, no. 13, pp. 2189-2199, 1999.

[44] M. L. Smith, I. T. Chen, Q. Zhan et al., "Interaction of the p53-regulated protein gadd45 with proliferating cell nuclear antigen," Science, vol. 266, no. 5189, pp. 1376-1380, 1994.

[45] U. Santhanam, A. Ray, and P. B. Sehgal, "Repression of the interleukin 6 gene promoter by $\mathrm{p} 53$ and the retinoblastoma susceptibility gene product," Proceedings of the National Academy of Sciences of the United States of America, vol. 88, no. 17, pp. 7605-7609, 1991.

[46] A. Zauberman, D. Flusberg, Y. Haupt, Y. Barak, and M. Oren, "A functional p53-responsive intronic promoter is contained within the human $m d m 2$ gene," Nucleic Acids Research, vol. 23, no. 14, pp. 2584-2592, 1995.

[47] J. Chen and I. Sadowski, "Identification of the mismatch repair genes PMS2 and MLH1 as p53 target genes by using serial analysis of binding elements," Proceedings of the National Academy of Sciences of the United States of America, vol. 102, no. 13, pp. 4813-4818, 2005.

[48] S. J. Scherer, S. M. Maier, M. Seifert et al., "p53 and c-Jun functionally synergize in the regulation of the DNA repair gene hMSH2 in response to UV,' The Journal of Biological Chemistry, vol. 275, no. 48, pp. 37469-37473, 2000.

[49] K. H. Moberg, W. A. Tyndall, and D. J. Hall, "Wild-type murine p53 represses transcription from the murine c-myc promotor in a human glial cell line," Journal of Cellular Biochemistry, vol. 49, no. 2, pp. 208-215, 1992.

[50] G. F. Morris, J. R. Bischoff, and M. B. Mathews, “Transcriptional activation of the human proliferating-cell nuclear antigen promoter by p53," Proceedings of the National Academy of Sciences of the United States of America, vol. 93, no. 2, pp. 895-899, 1996.

[51] E. Oda, R. Ohki, H. Murasawa et al., "Noxa, a BH3-only member of the Bcl-2 family and candidate mediator of p53-induced apoptosis," Science, vol. 288, no. 5468, pp. 1053-1058, 2000.

[52] M. Fiscella, H. Zhang, S. Fan et al., "Wip1, a novel human protein phosphatase that is induced in response to ionizing radiation in a p53-dependent manner," Proceedings of the National Academy of Sciences of the United States of America, vol. 94, no. 12, pp. 6048-6053, 1997.

[53] C. Li, M. Lin, and J. Liu, "Identification of PRC1 as the p53 target gene uncovers a novel function of p53 in the regulation of cytokinesis," Oncogene, vol. 23, no. 58, pp. 9336-9347, 2004.

[54] M. Zhan, D. Yu, J. Liu, J. Hannay, and R. E. Pollock, “Transcriptional repression of protein kinase $\mathrm{C} \alpha$ via Sp1 by wild type $\mathrm{p} 53$ is involved in inhibition of multidrug resistance $1 \mathrm{P}$-glycoprotein phosphorylation," The Journal of Biological Chemistry, vol. 280, no. 6, pp. 4825-4833, 2005.

[55] V. Stambolic, D. MacPherson, D. Sas et al., "Regulation of PTEN transcription by p53," Molecular Cell, vol. 8, no. 2, pp. 317-325, 2001.

[56] P. S. Kho, Z. Wang, L. Zhuang et al., "p53-regulated transcriptional program associated with genotoxic stress-induced apoptosis," Journal of Biological Chemistry, vol. 279, no. 20, pp. 21183-21192, 2004.

[57] Y. Shiio, T. Yamamoto, and N. Yamaguchi, "Negative regulation of $\mathrm{Rb}$ expression by the $\mathrm{p} 53$ gene product," Proceedings of the National Academy of Sciences of the United States of America, vol. 89, no. 12, pp. 5206-5210, 1992.

[58] A. V. Budanov and M. Karin, "p53 target genes sestrinl and sestrin2 connect genotoxic stress and mTOR signaling," Cell, vol. 134, no. 3, pp. 451-460, 2008.

[59] R. Ohki, J. Nemoto, H. Murasawa et al., "Reprimo, a new candidate mediator of the p53-mediated cell cycle arrest at the $\mathrm{G}_{2}$ phase," The Journal of Biological Chemistry, vol. 275, no. 30, pp. 22627-22630, 2000.

[60] J. Lin, Q. Yang, Z. Yan et al., "Inhibiting S100B restores p53 levels in primary malignant melanoma cancer cells," The Journal of Biological Chemistry, vol. 279, no. 32, pp. 34071-34077, 2004.

[61] L. Brown, P. P. Ongusaha, H.-G. Kim et al., "CDIP, a novel proapoptotic gene, regulates TNF $\alpha$-mediated apoptosis in a p53dependent manner," The EMBO Journal, vol. 26, no. 14, pp. 3410-3422, 2007. 
[62] R. Zhao, K. Gish, M. Murphy et al., "Analysis of p53-regulated gene expression patterns using oligonucleotide arrays," Genes \& Development, vol. 14, no. 8, pp. 981-993, 2000.

[63] C. D. Lopez, Y. Ao, L. H. Rohde et al., "Proapoptotic p53interacting protein $53 \mathrm{BP} 2$ is induced by UV irradiation but suppressed by p53," Molecular and Cellular Biology, vol. 20, no. 21, pp. 8018-8025, 2000.

[64] D. C. Harmes, E. Bresnick, E. A. Lubin et al., "Positive and negative regulation of deltaN-p63 promoter activity by $\mathrm{p} 53$ and deltaN-p63-alpha contributes to differential regulation of p53 target genes," Oncogene, vol. 22, no. 48, pp. 7607-7616, 2003.

[65] T. J. Grob, U. Novak, C. Maisse et al., "Human $\Delta$ Np73 regulates a dominant negative feedback loop for TAp73 and p53," Cell Death and Differentiation, vol. 8, no. 12, pp. 1213-1223, 2001.

[66] X. Chen, Y. Zheng, J. Zhu, J. Jiang, and J. Wang, "p73 is transcriptionally regulated by DNA damage, p53, and p73," Oncogene, vol. 20, no. 6, pp. 769-774, 2001.

[67] D. Israeli, E. Tessler, Y. Haupt et al., "A novel p53-inducible gene, PAG608, encodes a nuclear zinc finger protein whose overexpression promotes apoptosis," The EMBO Journal, vol. 16, no. 14, pp. 4384-4392, 1997.

[68] P. D. Lisachev, V. O. Pustylnyak, M. B. Shtark, and O. I. Epstein, "Induction of S100B gene expression in long-term potentiation in the hippocampal CA1 field depends on activity of NMDA receptors," Bulletin of Experimental Biology and Medicine, vol. 154, no. 4, pp. 485-488, 2013.

[69] O. O. Sokolova, M. B. Shtark, P. D. Lisachev, V. O. Pustylnyak, I. R. Pan, and O. I. Epstein, "Expression of S100B and S100A6 genes during long-term posttetanic potentiation in the hippocampus," Bulletin of Experimental Biology and Medicine, vol. 148, no. 2, pp. 227-229, 2009.

[70] Y. Y. Huang and E. R. Kandel, "Recruitment of long-lasting and protein kinase A-dependent long-term potentiation in the CA1 region of hippocampus requires repeated tetanization," Learning \& Memory, vol. 1, no. 1, pp. 74-82, 1994.

[71] L. Biderman, J. L. Manley, and C. Prives, "Mdm2 and MdmX as regulators of gene expression," Genes \& Cancer, vol. 3, no. 3-4, pp. 264-273, 2012.

[72] C. S. Park, R. Gong, J. Stuart, and S.-J. Tang, "Molecular network and chromosomal clustering of genes involved in synaptic plasticity in the hippocampus," Journal of Biological Chemistry, vol. 281, no. 40, pp. 30195-30211, 2006.

[73] J. E. Ploski, K. W. Park, J. Ping, M. S. Monsey, and G. E. Schafe, "Identification of plasticity-associated genes regulated by Pavlovian fear conditioning in the lateral amygdala," Journal of Neurochemistry, vol. 112, no. 3, pp. 636-650, 2010.

[74] M. M. Ryan, S. E. Mason-Parker, W. P. Tate, W. C. Abraham, and J. M. Williams, "Rapidly induced gene networks following induction of long-term potentiation at perforant path synapses in vivo," Hippocampus, vol. 21, no. 5, pp. 541-553, 2011.

[75] M. M. Ryan, B. Ryan, M. Kyrke-Smith et al., "Temporal profiling of gene networks associated with the late phase of long-term potentiation in vivo," PLoS ONE, vol. 7, no. 7, Article ID e40538, 2012.

[76] E. S. Lein, X. Zhao, and F. H. Gage, "Defining a molecular atlas of the hippocampus using DNA microarrays and high-throughput in situ hybridization," The Journal of Neuroscience, vol. 24, no. 15, pp. 3879-3889, 2004.

[77] E. D. Leonardo, J. W. Richardson-Jones, E. Sibille, A. Kottman, and R. Hen, "Molecular heterogeneity along the dorsal-ventral axis of the murine hippocampal CA1 field: a microarray analysis of gene expression," Neuroscience, vol. 137, no. 1, pp. 177-186, 2006.

[78] N. Maggio and M. Segal, "Unique regulation of long term potentiation in the rat ventral hippocampus," Hippocampus, vol. 17, no. 1, pp. 10-25, 2007.

[79] T. Riley, E. Sontag, P. Chen, and A. Levine, "Transcriptional control of human p53-regulated genes," Nature Reviews Molecular Cell Biology, vol. 9, no. 5, pp. 402-412, 2008.

[80] E. Miyamoto, "Molecular mechanism of neuronal plasticity: induction and maintenance of long-term potentiation in the hippocampus," Journal of Pharmacological Sciences, vol. 100, no. 5, pp. 433-442, 2006.

[81] V. P. Sukhatme, X. M. Cao, L. C. Chang et al., "A zinc finger-encoding gene coregulated with $c$-fos during growth and differentiation, and after cellular depolarization," Cell, vol. 53, no. 1, pp. 37-43, 1988.

[82] A. Quiñones, K. U. Dobberstein, and N. G. Rainov, “The egr-1 gene is induced by DNA-damaging agents and non-genotoxic drugs in both normal and neoplastic human cells," Life Sciences, vol. 72, no. 26, pp. 2975-2992, 2003.

[83] I. de Belle, R.-P. Huang, Y. Fan, C. Liu, D. Mercola, and E. D. Adamson, "P53 and Egr-1 additively suppress transformed growth in HT1080 cells but Egr-1 counteracts p53-dependent apoptosis," Oncogene, vol. 18, no. 24, pp. 3633-3642, 1999.

[84] M. Pignatelli, R. Luna-Medina, A. Pérez-Rendón, A. Santos, and A. Perez-Castillo, "The transcription factor early growth response factor-1 (EGR-1) promotes apoptosis of neuroblastoma cells," The Biochemical Journal, vol. 373, no. 3, pp. 739-746, 2003.

[85] E. Bálint, S. Bates, and K. H. Vousden, "Mdm2 binds $\mathrm{p} 73 \alpha$ without targeting degradation," Oncogene, vol. 18, no. 27, pp. 3923-3929, 1999. 

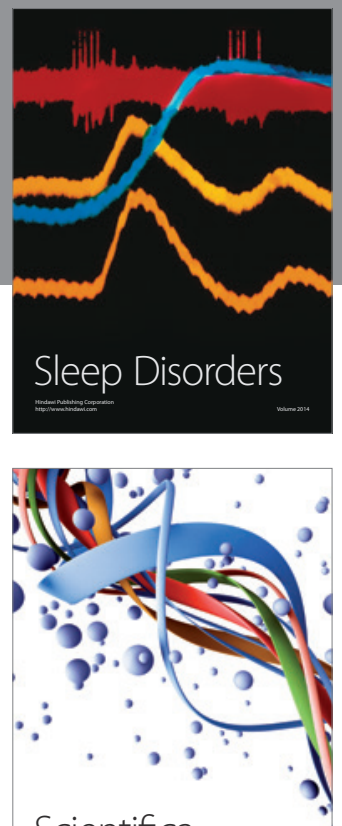

Scientifica
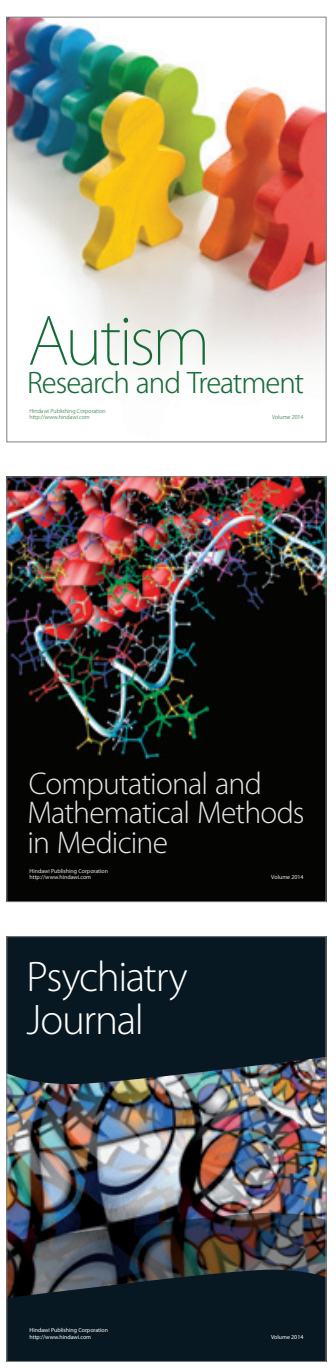
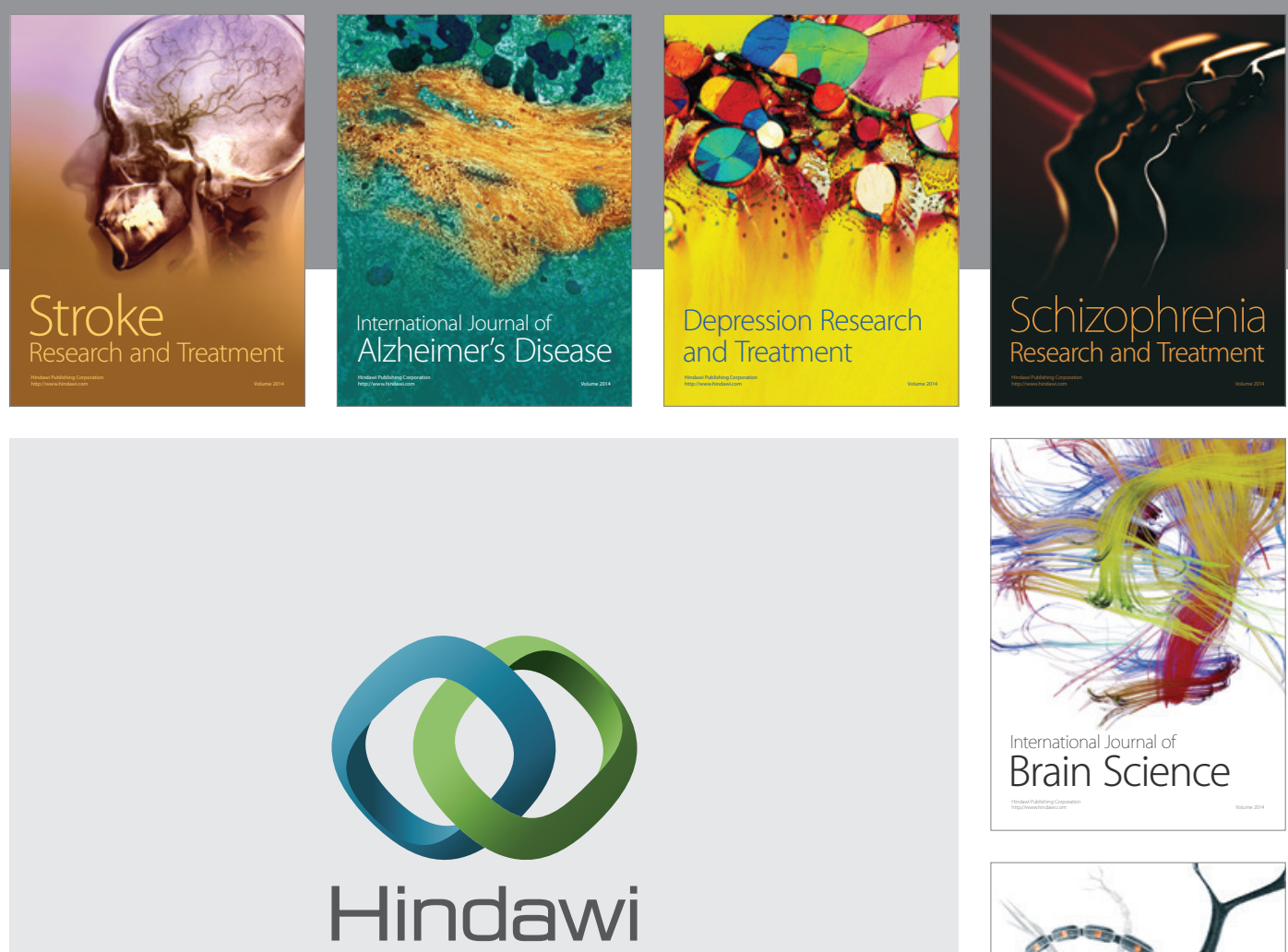

Submit your manuscripts at

http://www.hindawi.com
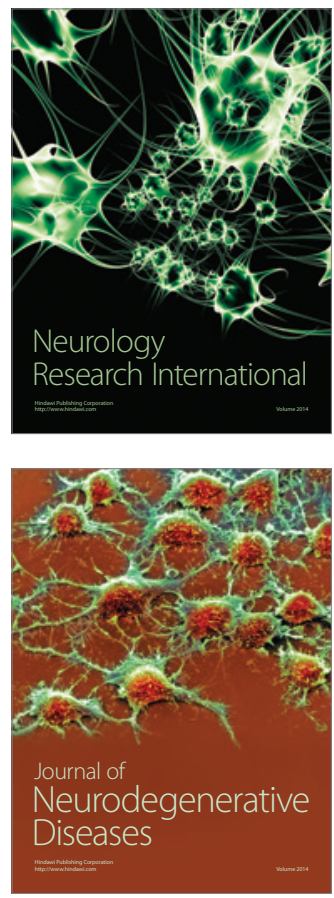

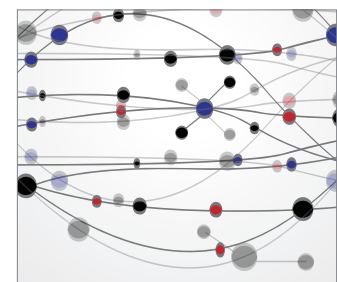

The Scientific World Journal
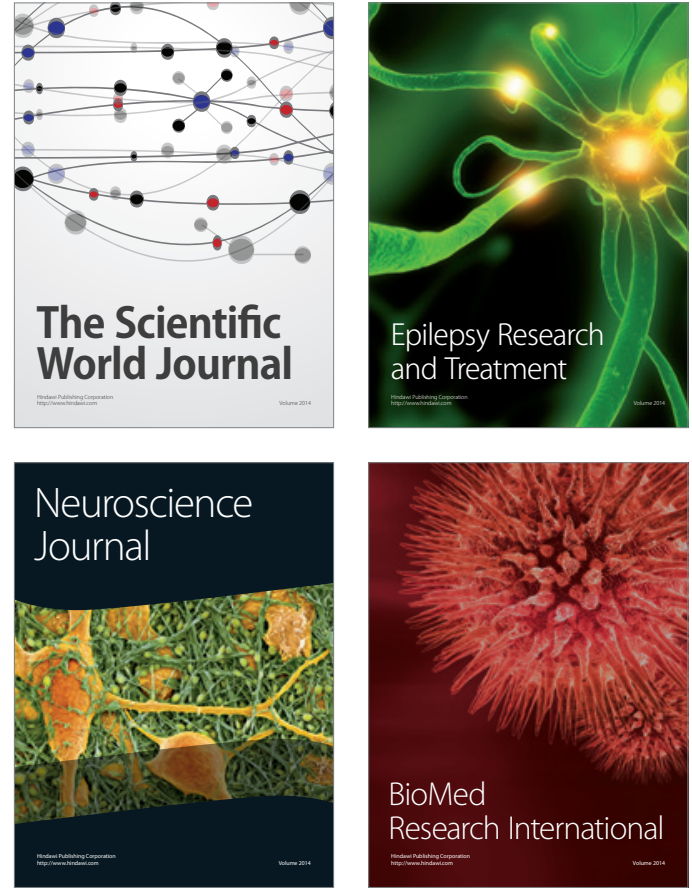

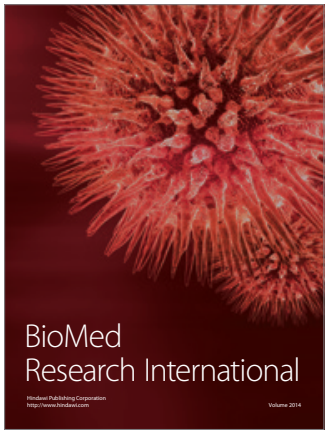

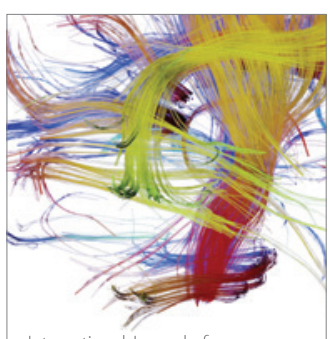

Brain Science

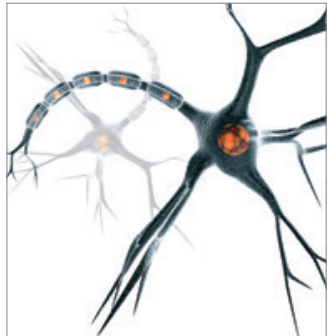

Neural Plasticity
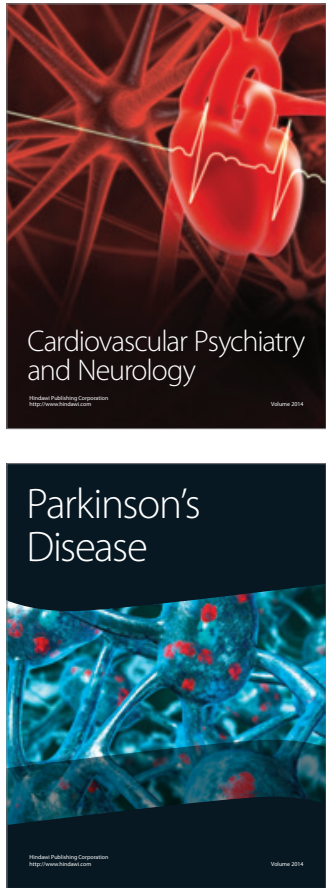